\title{
Dynamic Assessment of Vibration of Tooth Modification Gearbox Using Grey Bootstrap Method
}

\author{
Hui-liang Wang, ${ }^{1}$ Xiao-zhong Deng, ${ }^{2} \mathrm{Ju}_{-b o} \mathrm{Li}^{2},{ }^{2}$ and Jian-jun Yang ${ }^{2}$ \\ ${ }^{1}$ School of Mechanical Engineering, Northwestern Polytechnical University, Xian 710072, China \\ ${ }^{2}$ School of Mechatronics Engineering, Henan University of Science and Technology, Luoyang, Henan 471003, China \\ Correspondence should be addressed to Xiao-zhong Deng; dxz01@163.com
}

Received 28 May 2015; Revised 3 August 2015; Accepted 4 August 2015

Academic Editor: Jussi Sopanen

Copyright (c) 2015 Hui-liang Wang et al. This is an open access article distributed under the Creative Commons Attribution License, which permits unrestricted use, distribution, and reproduction in any medium, provided the original work is properly cited.

\begin{abstract}
The correlation analysis between gear modification and vibration characteristics of transmission system was difficult to quantify; a novel small sample vibration of gearbox prediction method based on grey system theory and bootstrap theory was presented. The method characterized vibration base feature of tooth modification gearbox by developing dynamic uncertainty, estimated true value, and systematic error measure, and these parameters could indirectly dynamically evaluate the effect of tooth modification. The method can evaluate the vibration signal of gearbox with installation of no tooth modification gear and topological modification gear, respectively, considering that $100 \%$ reliability is the constraints condition and minimum average uncertainty is the target value. Computer simulation and experiment results showed that vibration amplitude of gearbox was decreased partly due to topological tooth modification, and each value of average dynamic uncertainty, mean true value, and systematic error measure was smaller than the no tooth modification value. The study provided an important guide for tooth modification, dynamic performance optimization.
\end{abstract}

\section{Introduction}

With the development of high speed and heavy load gear transmission, more and more people pay attention to the problems of vibration and noise. It demands harshly the vibration in aviation, marine, and other areas of transmission system; how to assess and reduce transmission system vibration is a direction of current research. Modification technology as the effective means of improving the performance of gear is paid attention early; it can better improve meshing condition by tooth surface modification, effectively prevent edge contact, and reduce vibration and noise [1-3].

In the transmission process, the gearbox vibration has become the main incentive source of transmission system because of the gear mesh stiffness and error incentive, so the prediction of the dynamic characteristics of the gearbox vibration is extremely important [4-6]. Kato [7] introduced the FEM/BEM method of predicting vibration and noise radiation, which was consistent with the experimental results. Zhou et al. [8] proposed formula-fitting method for predicting noise radiation, which can directly predict noise by the basic system parameters of the gearbox. Tuma [9] analyzed the incentive component and prediction method of the gearbox vibration noise and proposed the method of vibration isolation from the tooth geometric shapes, stiffness of the gearbox, and so on. However, the solution of gearbox vibration noise quantitative assessment needs to consume a lot of computing resources, time, and effort. Xia et al. [10] established a dynamic assessment model $\operatorname{GBM}(1,1)$ for manufacturing errors using grey bootstrap method, in order to solve the problem of predicting manufacturing errors with poor information. Wang et al. [11] gained the predictions of calibration data of all error sources by a grey bootstrap fusion model, which can accurately predict measurements of the material Brinell hardness. Grey bootstrap method has been used in the aspects of dynamic assessment of bearing vibration [12], uncertain assessment of virtual instrument in small sample measuring [13], and dynamic predicting of the shake of radial sloshing error [14], which coincided with the actual measurements. But gearbox vibration dynamic predicting by grey theory and grey bootstrap has not been studied $[15,16]$. 
This paper established grey bootstrap dynamic assessment model $\operatorname{GBM}(1,1)$ [17] by grey predicting model $\operatorname{GM}(1,1)[18,19]$ and bootstrap theory and dynamically assessed gearbox vibration in a small sample with poor information. Compared to no modification gear, this paper indirectly analyzed the impact of modification gear on the dynamic characteristics of the transmission system and demonstrated the accuracy of the dynamic assessment by conducted experimental investigation.

\section{Dynamic Predicting Model GBM(1, 1)}

2.1. Principle of $\operatorname{GBM}(1,1)$. Due to machine errors, heat treatment distortions, variation of cutting forces, and other unpredictable factors reduce gear quality and cause unfavorable displacement of tooth contact and increased transmission errors, resulting in edge contact, highly concentrated stresses, and vibration. Tooth modification is used to prevent increased levels of noise and vibration due to the deformation of the teeth. So it is important to evaluate the uncertainty in measurement of vibration of gearbox. The principle of grey bootstrap model $\operatorname{GBM}(1,1)$ is shown in Figure 1 , which is a method combining the bootstrap theory with grey predicting model $\operatorname{GM}(1,1)$ to predict measurement uncertainties.

\subsection{Building Bootstrap Resampling Samples of Vibration.} In the gearbox, gear and bearing are the factors causing vibrations. By replacing different modification gears, gearbox vibration will be much different. In the large-volume gear grinding process, the processed products in production process can be seen as an infinite population; at the time $t$ replacing the gear of the gearbox, data series vector of gearbox vibration can be obtained and given by

$$
\mathbf{Y}=\{y(t)\} ; \quad t=1,2, \ldots,
$$

where $y(t)$ is the original data of the vibration of the gearbox at the time $t$. To estimate the uncertainty at the time $t$ by means of $i$ vibration data, which are close and before the time $t$ (including the time $t$ ), the data series vector at the time $t$ is constituted and is expressed by

$$
\mathbf{Y}_{i}=\left\{y_{i}(u)\right\} ; \quad u=t-i+1, t-i+2, \ldots, t ; i \leq t
$$

where $u$ is the time $u$ and $i$ is the data number of subseries $\mathbf{Y}_{i}$ of dynamic predicting. In bootstrap statistics, $\mathbf{Y}_{i}$ is the initial sample and $i$ is the capacity of sample.

According to the bootstrap theory, randomly extracting $i$ times vibration data of gearbox with equal probability from $\mathbf{Y}_{i}$ on sampling with replacement, a bootstrap sample with $i$ vibration data is formed. Repeating $B$ times in a row, the $B$ bootstrap resampling samples can be obtained and numerically represented as

$$
\mathbf{B}_{\text {Bootstrap }}=\left(\mathbf{B}_{1}, \mathbf{B}_{2}, \ldots, \mathbf{B}_{b}, \ldots, \mathbf{B}_{B}\right),
$$

where $\mathbf{B}_{b}$ is the $b$ th bootstrap sample, and

$$
\mathbf{B}_{b}=\left\{b_{b}(u)\right\} ; \quad b=1,2, \ldots, B ;
$$

here $b_{b}(u)$ is the $u$ th bootstrap resampling sample of vibration data within $\mathbf{B}_{b}$; $B$ is the number of the bootstrap resampling samples.

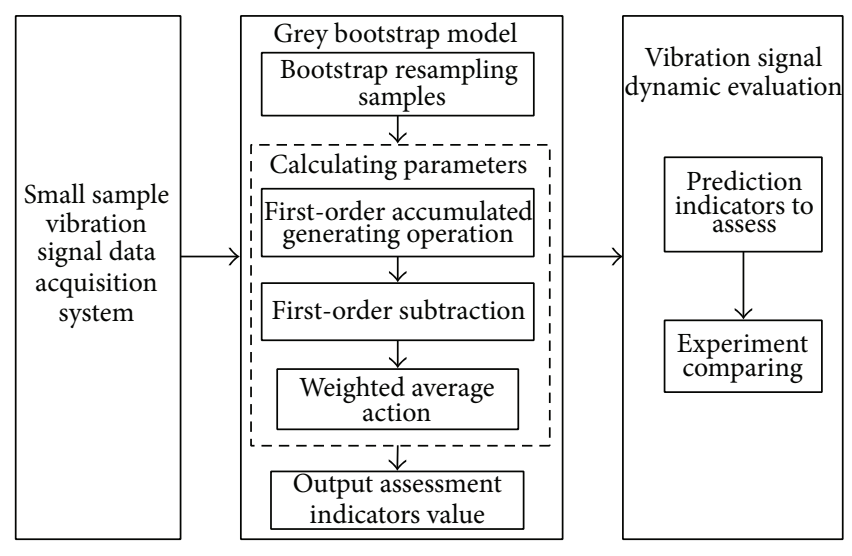

FIGURE 1: Schematic of prediction for gearbox vibration of poor information.

2.3. Calculating Parameters of GBM. According to the grey system theory, the first-order accumulated generating operation of $\mathbf{B}_{b}$ is defined as

$$
\begin{aligned}
& \mathbf{S}_{b}=\left\{s_{b}(u)\right\}=\left\{\sum_{j=t-i+1}^{u} B_{b}(j)\right\} ; \\
& u=t-i+1, t-i+2, \ldots, t, i \leq t ; \quad b=1,2, \ldots, B .
\end{aligned}
$$

The grey generated model can be described by the differential equation which is given by

$$
\frac{d s_{b}(t)}{d t}+k_{1} s_{b}(t)=k_{2}
$$

where $t$ is time variable, $k_{1}$ and $k_{2}$ are the coefficients to be estimated, and in addition $k_{1}$ is not equal to zero.

Substitute the increment with the differential, so

$$
\frac{d s_{b}(t)}{d t}=\left.\frac{\Delta s_{b}(t)}{\Delta t}\right|_{\Delta t=1}=s_{b}(t+1)-s_{b}(t)=b_{b}(t+1) .
$$

Suppose average generated series vector is

$$
\begin{aligned}
\mathbf{Z}_{b}=\left\{z_{b}(u)\right\}=\left\{\frac{s_{b}(u)+s_{b}(u-1)}{2}\right\} ; \\
u=t-i+2, t-i+3, \ldots, t .
\end{aligned}
$$

In the initial condition $s_{b}(t-i+1)=b_{b}(t-i+1)$, suppose grey differential equation least-squares solution is

$$
\begin{aligned}
& \widehat{s}_{b}(j+1)=\left[b_{b}(t-i+1)-\frac{k_{2}}{k_{1}}\right] e^{-k_{1} j}+\frac{k_{2}}{k_{1}} ; \\
& j=t-1, t,
\end{aligned}
$$

where the coefficients, $k_{1}$ and $k_{2}$, are given by

$$
\begin{aligned}
\left(k_{1}, k_{2}\right)^{T} & =\left(\mathbf{D}^{T} \mathbf{D}\right)^{-1} \mathbf{D}^{T}\left(Y_{b}\right)^{T} ; \\
\mathbf{D} & =\left(-\mathbf{Z}_{b}, \mathbf{I}\right)^{T} ; \quad \mathbf{I}=(1,1, \ldots, 1) .
\end{aligned}
$$


So at the $w$ th time the predicted value is as follows:

$$
\widehat{b}_{b}(w)=\widehat{s}_{b}(w)-\widehat{s}_{b}(w-1) ; \quad w=t+1 .
$$

Series vector of the $B$ data at the $w$ th time is as follows:

$$
\widehat{\mathbf{S}}_{t+1}=\left\{\widehat{b}_{b}(t+1)\right\} ; \quad b=1,2, \ldots, B .
$$

The $B$ data of $\widehat{\mathbf{S}}_{t+1}$ are established in the histogram; the probability density distribution curve can be obtained. At the $w$ th time, let $B$ data be divided into $K$ groups by a certain interval; $S_{k}$ is the class midvalue of $k$ th group; the frequency in the group is $f_{k}$. Then, in the time $t+1$ the true predicted value can be calculated as a weighted average:

$$
S_{0}=S_{0}(t+1)=\sum_{k=1}^{K} S_{k} f_{k} .
$$

2.4. Output Assessment Indicators Value. The model characterizes vibration of gearbox by developing six parameters, such as estimated true value, interval dynamic uncertainty, average uncertainty, average true value, and system trend error measure. Assume the significance level is $\alpha$; the confidence level can be given as follows:

$$
P=(1-\alpha) \times 100 \% .
$$

At the time $t+1$ an estimated interval of true value of vibration at the confidence degree $P$ is as follows:

$$
\left[S_{L}, S_{U}\right]=\left[S_{L}(t+1), S_{U}(t+1)\right]=\left[S_{\alpha / 2}, S_{1-\alpha / 2}\right] \text {, }
$$

where $S_{\alpha / 2}$ is the value of gearbox vibration $y_{i}$ corresponding to a probability $\alpha / 2 ; S_{1-\alpha / 2}$ is the value of gearbox vibration $y_{i}$ corresponding to a probability $1-\alpha / 2 ; S_{L}$ is the low boundary of the estimated interval; $S_{U}$ is the upper boundary of the estimated interval.

When predicting, the system inputs the first data $n=N$; if there are $h$ vibration data outside the estimated interval $\left[S_{L}, S_{U}\right]$, the predicted accuracy $P_{B}$ is expressed as follows:

$$
P_{B}=\frac{(1-h)}{(N-m)} \times 100 \% \text {. }
$$

The expanded uncertainty of gearbox vibration at time $t$ is defined as

$$
U=U(t+1)=S_{U}-S_{L}
$$

where $U$ is the estimated uncertainty at the time $t$ under the $P$ confidence level, and it is, namely, dynamic uncertainty.

If $P=100 \%$, the maximum $U$ will be received, but the larger $U$ is, the farther $\left[S_{L}, S_{U}\right]$ get away from the true value. Therefore, the average uncertainty is defined as

$$
\left.\bar{U}\right|_{(i, B, P)}=\left.\left(\frac{1}{N-i}\right) \sum_{k=i+1}^{N} U(k)\right|_{P_{B}=100 \%} .
$$

In order to assess the size of the vibration value of the gearbox, $\bar{S}_{0}$ is defined as

$$
\bar{S}_{0}=\left(\frac{1}{N-i}\right) \sum_{k=i+1}^{N} \bar{S}_{0}(k) .
$$

Here $\bar{S}_{0}$ is the mean true value of the gearbox vibration.

In order to assess the impact of trends in terms of vibration, $d S_{0}$ is defined as

$$
d S_{0}=\max _{t} S_{0}(t)-\min _{t} S_{0}(t),
$$

where $d S_{0}$ is the range value of the estimated value of vibration and is, namely, the system error measure.

\section{Gearbox Vibration Signals}

Gearbox contains gears, bearings, shafts, and other components and during operation gear will produce meshing impact and cause vibration corresponding to gear mesh frequency. Vibration signals of gearbox are measured from the bearing housing, containing the meshing vibration response of the gear and also including vibration produced by the rolling bearing and the response of other incentives in gearbox which is expressed as

$$
y(t)=y_{\text {gear }}(t)+y_{\text {bearing }}(t)+y_{a}(t),
$$

where $y_{\text {gear }}(t)$ is the meshing vibration response of the gear under the normal condition; $y_{\text {bearing }}(t)$ is the meshing vibration response of the bearing; and $y_{a}(t)$ is the vibration response of the random incentives.

Namely, in the certain condition, the speed and load are determined, gear meshing vibration response can be expressed as gear mesh frequency $f_{\text {mesh }}$, and its harmonic frequency in the form of series is expressed as

$$
\begin{aligned}
y_{\text {gear }}(t)= & \sum_{m=0}^{M} X_{m}\left\{1+a_{m}(t)\right\} \\
& \cdot \cos \left\{2 \pi m f_{\text {mesh }}+\Phi_{m}+b_{m}(t)\right\},
\end{aligned}
$$

where $X_{m}$ is the meshing frequency component amplitude of order $m ; \Phi_{m}$ is phase; $a_{m}(t)$ and $b_{m}(t)$ are additional amplitude and phase modulation generated errors incentives. The mesh frequency $f_{\text {mesh }}$ can be expressed as

$$
f_{\text {mesh }}=z f_{z}=z \frac{n}{60}
$$

where $f_{z}$ is gear rotation frequency, $z$ is gear tooth number, and $n$ is gear speed ( $r / \mathrm{min})$.

\section{Experimental Study}

4.1. Gearbox Vibration Testing. Load platform consists of the gearbox, magnetic loader, adjustable motor, torque sensor, acceleration sensor, and sound level meter, whose load platform structure diagram has been shown in Figure 2 [20]. 
TABLE 1: Parameters of the gearbox.

\begin{tabular}{lcccc}
\hline Parameter & $\begin{array}{c}\text { Input shaft } \\
\text { Driving gear 1 }\end{array}$ & Driven gear 2 & Middle shaft & Output shaft \\
& 23 & 26 & 25 & Driving gear 3 \\
Driven gear 4
\end{tabular}

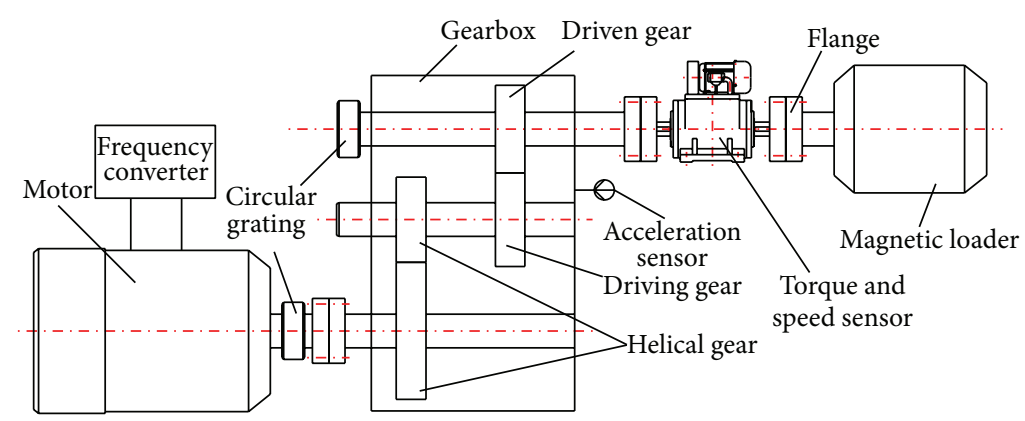

FIGURE 2: Schematic illustration of gearbox vibration test platform.

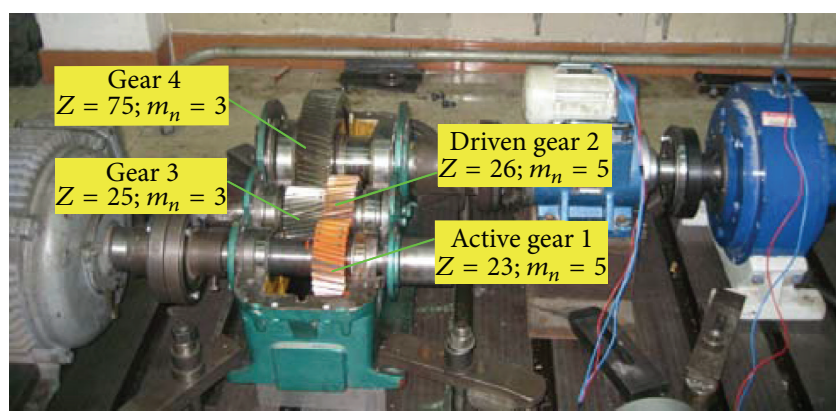

FIgURE 3: Gearbox internal structure.

The torque on gearbox output shaft is controlled by magnetic loader according to its current size, the torque and speed sensor measures the torque and speed of the output shaft, and sound pressure meter records the noise. Voltage signal measured by acceleration sensor is processed by the data acquisition instrument.

Internal structure of the gearbox is shown in Figure 3, consisting of a two-stage parallel shaft helical gear transmission; gearbox basic parameters are shown in Table 1. During the transmission process, because of the effect of the gear mesh stiffness and error excitation, the fluctuation of gear meshing force can cause the vibration of the system. The module of vibration acceleration vector sum in different directions on the box is defined as the vibration intensity $a_{\text {rms }}$ which is expressed as

$$
a_{\mathrm{rms}}=\sqrt{\left(\frac{\sum a_{x i}}{N_{x}}\right)^{2}+\left(\frac{\sum a_{y i}}{N_{y}}\right)^{2}+\left(\frac{\sum a_{z i}}{N_{z}}\right)^{2}},
$$

where $\sum a_{x i}, \sum a_{y i}$, and $\sum a_{z i}$ are the sum of acceleration vibration of each measuring point in different directions under the same work condition and $N_{x}, N_{y}$, and $N_{z}$ represent measuring points in different directions, respectively.

Gearbox vibration is affected by the working condition; for example, different speed and torque have their own vibration effects, respectively. Suppose the speed of the motor is $300 \mathrm{r} / \mathrm{min}$, the current of magnetic loader is $0.46 \mathrm{~A}$, and the output torque is $125 \mathrm{NM}$; the test apparatus is shown in Figure 4. Acceleration sensor in the gearbox bearing cap outer radial direction extracts vibration acceleration signals; the signals are dealt with through the signal conditioning and sent to the data acquisition system; the sampling frequency of the vibration signal is $5000 \mathrm{~Hz}$, without considering the impact of other errors in the measurement. The vibration signals of gearbox with 30 modification active gears (topographic modification parameters are shown in Table 2) and no modification driven gears which are, respectively, installed in the gearbox are detected. 


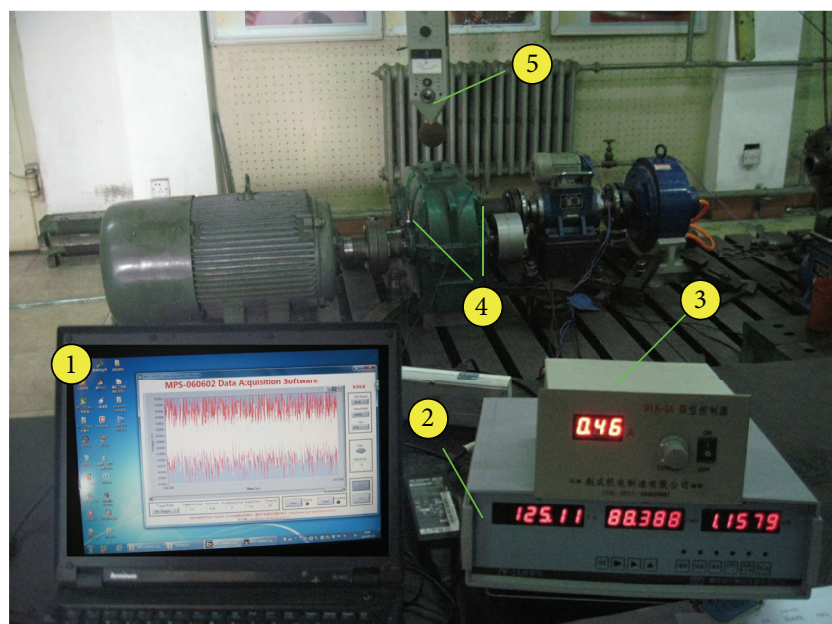

(1) Data acquisition software

(2) Torque sensor display

(3) Magnetic loader controller

FIgURE 4: Test structure of the active gearbox vibration.

Figures 5(a) and 6(a) are gearbox vibration time domain curves of no modification gear and modification gear, respectively. In Figure 5(a), the magnification factor is 10 in the measurement. Figures 5(b) and 6(b) are gearbox vibration frequency domain curves of no modification and modification gear, respectively. The main vibration frequencies of the gearbox are 115, 230, 345, and $460 \mathrm{~Hz}$. The amplitude of vibration, respectively, is $0.02037 \mathrm{~g}$ and $0.03056 \mathrm{~g}$, and gearbox vibration amplitude of tooth modification compared to no modification has decreased. Considering, from a single piece of modification and no modification gear, tooth modification has effect on gearbox vibration, for a detailed assessment of its vibration reduction effects, the grey dynamic self-assessment method has been used.

4.2. Gearbox Vibration Dynamic Assessment. Taking 30 sets of no modification gear and 30 sets of modification gear installed in the gearbox, respectively, the original data $Y$ of gearbox vibration is measured. The results of dynamic assessment are shown in Figures 7 and 8, where $n$ is the index of the groups of gears to be tested.

By calculating, the minimum parameter of average uncertainty $\bar{U}$ and evaluation results are obtained, which is shown in Table 3. The gearbox vibration mean value $S_{0 \text { mean }}$ of no tooth modification is large; the gearbox vibration mean value $S_{0 \text { mean }}$ of modification gear is decreased.

Figures $7(\mathrm{a})$ and $8(\mathrm{a})$ are the dynamic description of random volatility of the original data $Y$ for the estimated interval $\left[S_{L}, S_{U}\right]$ which reflected the trend of $Y$. $\left[S_{L}, S_{U}\right]$ can completely envelop the volatility of $Y$, indicating that $\operatorname{GBM}(1,1)$ can better describe the transient trend of gearbox vibration acceleration.

Figures 7(b) and 8(b) are the dynamic description of estimated true value $S_{0}$ for the trend change of $Y$. In Figure $7(\mathrm{~b})$, the volatility is increasing significantly from the
TABLe 2: Parameters of driven gear 2.

\begin{tabular}{lccc}
\hline Number & Parameter name & Unit & Driven gear 2 \\
\hline 1 & Top profile crowning $a_{\mathrm{mp}}$ & $1 / \mathrm{mm}$ & 0.001 \\
2 & Top limit angle $u_{c}$ & $\mathrm{rad}$ & 0.511 \\
3 & Bottom limit angle $u_{d}$ & $\mathrm{rad}$ & 0.145 \\
4 & Longitudinal crowning $a_{\mathrm{ml}}$ & $1 / \mathrm{mm}$ & 0.0008 \\
5 & Front limit $\theta_{a}$ & $\mathrm{rad}$ & 0.024 \\
6 & Back limit $\theta_{b}$ & $\mathrm{rad}$ & 0.138 \\
\hline
\end{tabular}

TABLE 3: Whole evaluation for gearbox vibration $\left(P_{B}=100 \%, i=4\right.$, and $B=3000$ ).

\begin{tabular}{lcccc}
\hline Gearbox & $P / \%$ & $U / 10^{-3} \mathrm{~g}$ & $S_{0 \text { mean }} / 10^{-3} \mathrm{~g}$ & $d S_{0} / 10^{-3} \mathrm{~g}$ \\
\hline No tooth modification & 73 & 5.87 & 30.46 & 3.88 \\
Tooth modification & 70 & 5.33 & 29.69 & 2.53 \\
Reduced percentage & $4.11 \%$ & $9.19 \%$ & $2.52 \%$ & $34.79 \%$ \\
\hline
\end{tabular}

20 th set of data; this process is reflected by $S_{0}$. For example, the system error is large, where $d S_{0}$ equals $0.00388 \mathrm{~g}$ in Table 3. In Figure 8(b), the volatility has a slight increase from the 20th set of data, but, compared to Figure 7(b), the volatility is somewhat flat and the system error is smaller, where $d S_{0}$ equals $0.00253 \mathrm{~g}$. All the above results show that $\operatorname{GBM}(1,1)$ can dynamically assess the instantaneous impact of system error on the gearbox vibration.

Figures $7(\mathrm{c})$ and $8(\mathrm{c})$ are the dynamic description of the uncertainty $U$ of $Y$. The larger the random volatility of $Y$ is, the larger the value of $U$ is. The uncertainty $U$ reflects the degree of data difference between time $t$ and time $t+1$, which is independent of the change trend of $S_{0}$. It shows that $\operatorname{GBM}(1,1)$ can dynamically separate systematic errors, but it does not regard the impact of systematic errors in the dynamic assessment.

Table 3 is an overall assessment of the gearbox vibration before and after gear modification, compared to the reduction amplitude of three parameters such as dynamic uncertainty, the average true value, and system error measure. The reduction amplitude of the system error measure $d S_{0}$ is more obvious, and it shows that the system error measure $d S_{0}$ is more sensitive to gearbox vibration, so it can be used as an effective parameter to judge the gear modification effect and help with the dynamic assessment of gear modification effect.

\section{Conclusions}

Based on grey prediction model $\operatorname{GM}(1,1)$ and bootstrap sampling method, to establish grey bootstrap dynamic assessment model $\operatorname{GBM}(1,1)$ of gearbox vibration with modification gear, it is a better solution to the problem of dynamic assessment of gear modification. Evaluation index system of six parameters has been established, such as estimated true value, interval dynamic uncertainty, average uncertainty, average true value, and system trend error measure. It is dynamically assessed with $100 \%$ reliability as constraints condition and minimum average uncertainty as the target value. According to the parameter of $\operatorname{GBM}(1,1)$ assessment shows 

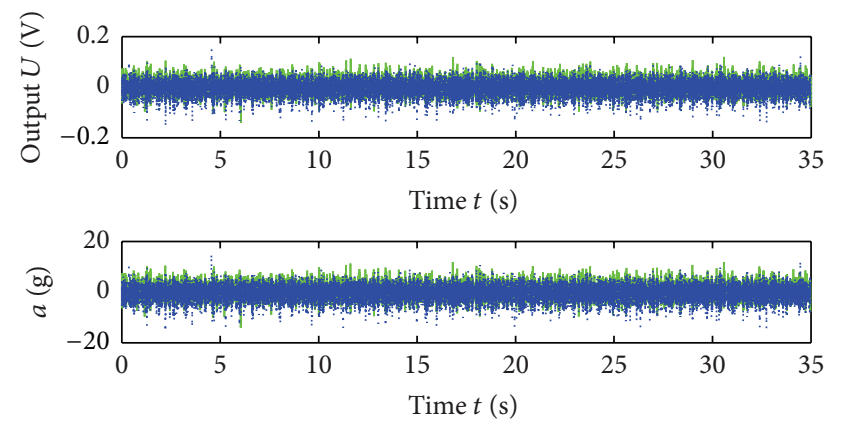

(a) Vibration acceleration signal

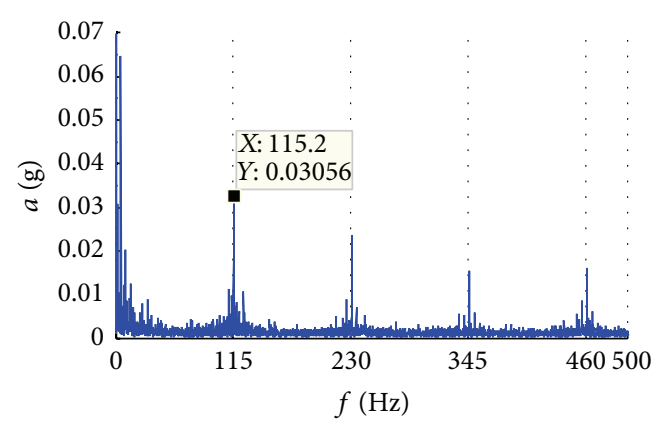

(b) Vibration spectrum

FIGURE 5: Vibration signal detection of gearbox with no modification gear.

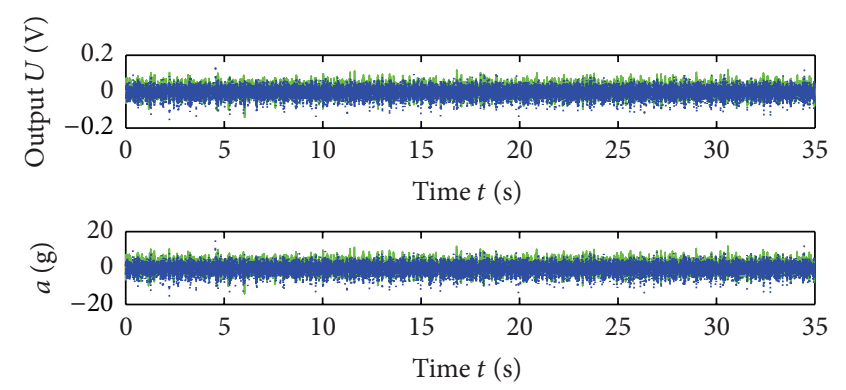

(a) Vibration acceleration signal

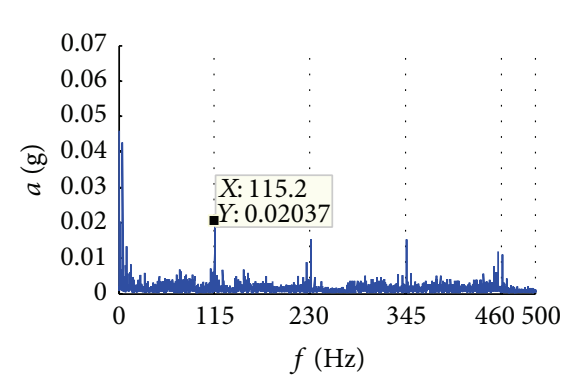

(b) Vibration spectrum

FIGURE 6: Vibration signal detection of gearbox with modification gear.

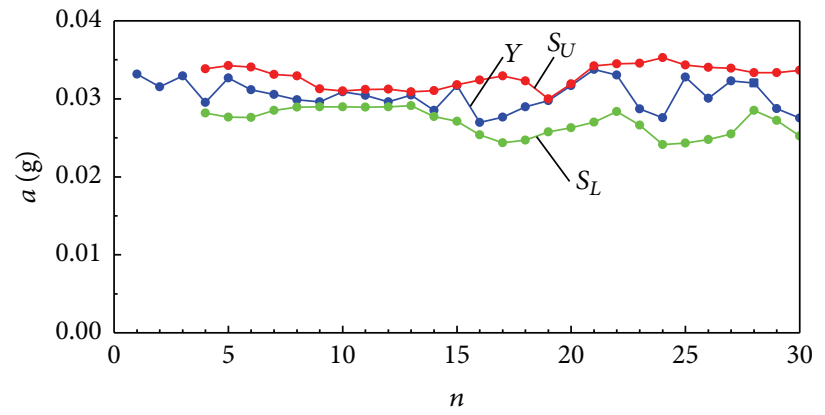

(a) Original data $Y$ and estimated interval $\left[S_{L}, S_{U}\right]$

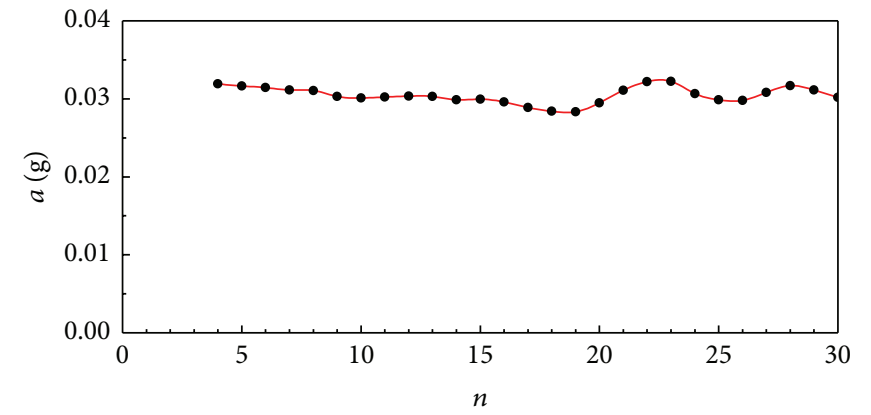

(b) Estimated true value $S_{0}$

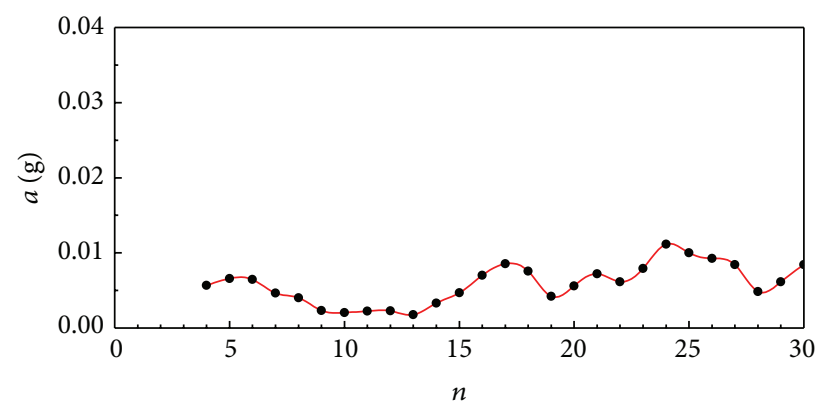

(c) Uncertainty $U$

FIGURE 7: Dynamic evaluation for vibration acceleration of gearbox with no modification gear. 


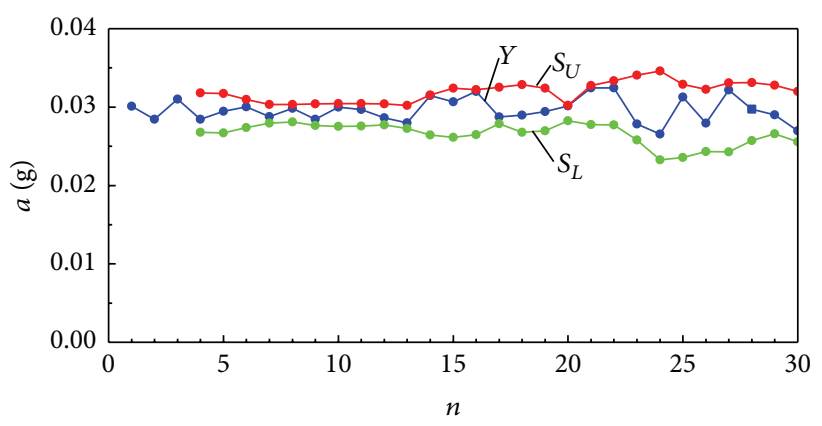

(a) Original data $Y$ and estimated interval $\left[S_{L}, S_{U}\right]$

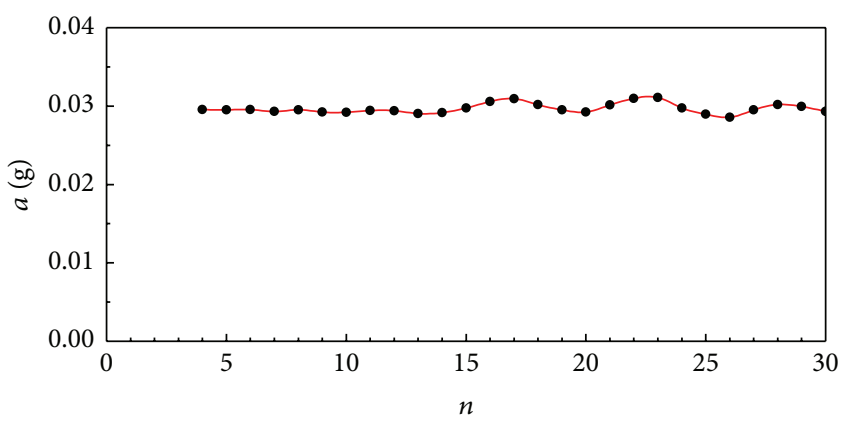

(b) Estimated true value $S_{0}$

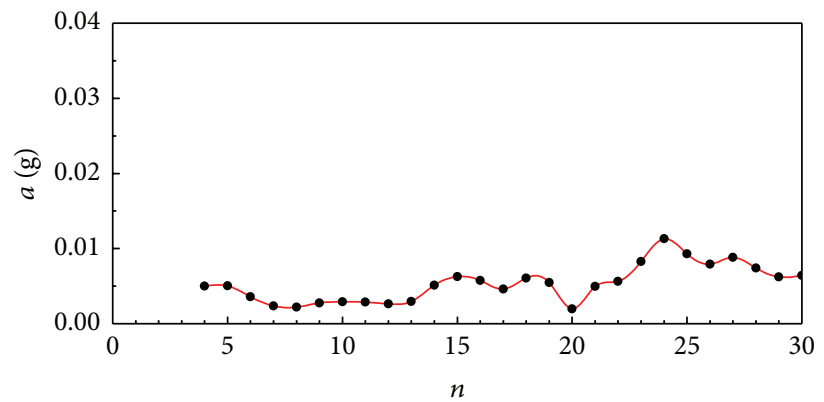

(c) Uncertainty $U$

FIGURE 8: Dynamic evaluation for vibration acceleration of gearbox with modification gear.

that a reasonable tooth modification has significant damping effect on gearbox and the amplitude is decreased. However, the effect of modification is different in other conditions; it is difficult to determine the optimal tooth modification in a variety of conditions. Modification parameters must be based on the actual working conditions in order to verify and correct the gearbox vibration to a minimum. The analysis of this paper provides the reference to determining the parameters of gear modification and dynamic assessment for the gearbox vibration.

\section{Conflict of Interests}

The authors declare that there is no conflict of interests regarding the publication of this paper.

\section{Acknowledgments}

The authors are grateful to the National Natural Science Foundation of China (Grants no. 51375144 and no. 51405135) and the Priority Project of Research in Universities in Henan Province (Grant no. 15A460021) for their financial support.

\section{References}

[1] Q. Fan, R. S. DaFoe, and J. W. Swanger, "Higher-order tooth flank form error correction for face-milled spiral bevel and hypoid gears," Journal of Mechanical Design, vol. 130, no. 7, Article ID 072601, 2008.

[2] J. Argyris, M. De Donno, and F. L. Litvin, "Computer program in Visual Basic language for simulation of meshing and contact of gear drives and its application for design of worm gear drive," Computer Methods in Applied Mechanics and Engineering, vol. 189, no. 2, pp. 595-612, 2000.

[3] C.-K. Lee, "Manufacturing process for a cylindrical crown gear drive with a controllable fourth order polynomial function of transmission error," Journal of Materials Processing Technology, vol. 209, no. 1, pp. 3-13, 2009.

[4] B. Lu, C.-C. Zhu, C.-S. Song, and H.-X. Wang, "Coupled nonlinear dynamic characteristics analysis and noise pre-estiation of a large burden marine gearbox," Journal of Vibration and Shock, vol. 28, no. 4, pp. 76-80, 2009.

[5] S. C. Kostic and M. Ognjanovic, "The noise structure of gear transmission units and the role of gearbox walls," FME Transactions, vol. 35, pp. 105-112, 2007.

[6] C. Yong, "Studies on noise and vibration of planetary gear drives for automatic transmission of transmission of passenger cars," Japan Machinery Essays, vol. 66, no. 642, pp. 634-639, 2000.

[7] M. Kato, K. Inoue, and K. Shibata, "Evaluation of sound power radiated by a gearbox," in Proceedings of the International Gearing Conference (Inter Gearing '94), pp. 69-74, Newcastle, UK, September 1994.

[8] J.-X. Zhou, W.-L. Sun, and X.-J. Wan, "Fornula-fitting method for predicting gear reducer noise radiation," Journal of Vibration and Shock, vol. 33, no. 7, pp. 174-180, 2014.

[9] J. Tuma, "Gearbox noise and vibration prediction and control," International Journal of Acoustics and Vibrations, vol. 14, no. 2, pp. 1-11, 2009.

[10] X. T. Xia, X. Y. Chen, and Y. Z. Zhang, "Dynamic prediction for manufacturing errors using grey bootstrp," Journal of Sichuan University: Engineering Science, vol. 39, no. 3, pp. 160-165, 2007.

[11] Z. Y. Wang, L. Y. Ge, J. Tong, and T. Xi, "Error predicting for material Brinell hardness measurement of poor information 
based on grey bootstrap method," Journal of Beijing University of Aeronautics and Astronautics, vol. 36, no. 5, pp. 524-528, 2010.

[12] X. T. Xia, X. Y. Chen, and Y. Z. Zhang, "Dynamic assessment and diagnosis of vibration of rolling bearings using grey bootstrap," Journal of Aerospace Power, vol. 22, no. 1, pp. 156-162, 2007.

[13] Z. Y. Wang, "Novel uncertainty-evaluation method of virtual instrument small sample size," Journal Testing and Evaluation, vol. 36, no. 3, pp. 101454-101461, 2008.

[14] L. Y. Ge, W. Zhao, and Z. F. Xu, "Error predicting for dynamic measurement of poor information based on grey bootstrap method," Transactions of the Chinese Society of Agricultural Machinery, vol. 42, no. 7, pp. 210-219, 2011.

[15] K.-N. Wei, L.-G. Yao, and Z.-H. Wu, "Research on products life cycle prediction based on grey theory," Computer Integrated Manufacturing Systems, vol. 11, no. 10, pp. 1491-1495, 2005.

[16] E. T. Hua, K. Zhou, and Y. L. Fei, "Multi-objective optimization for automotive door parameters based on grey theory," Computer Integrated Manufacturing Systems, vol. 18, no. 3, pp. 486491, 2012.

[17] J. L. Deng, "Introduction to grey system theory," The Journal of Grey System, vol. 1, no. 1, pp. 1-24, 1989.

[18] B. Efron, "Bootstrap methods," The Annals of Statistics, vol. 7, no. 1, pp. 1-36, 1979.

[19] J. J. Reeves, "Bootstrap prediction intervals for ARCH models," International Journal of Forecasting, vol. 21, no. 2, pp. 237-248, 2005.

[20] H.-L. Wang, X.-Z. Deng, J.-J. Yang, K. Xu, J.-X. Su, and Q. Chen, "Form grinding and experiment on segment topographic modification gear," Journal of Aerospace Power, vol. 29, no. 12, pp. 3000-3008, 2014. 

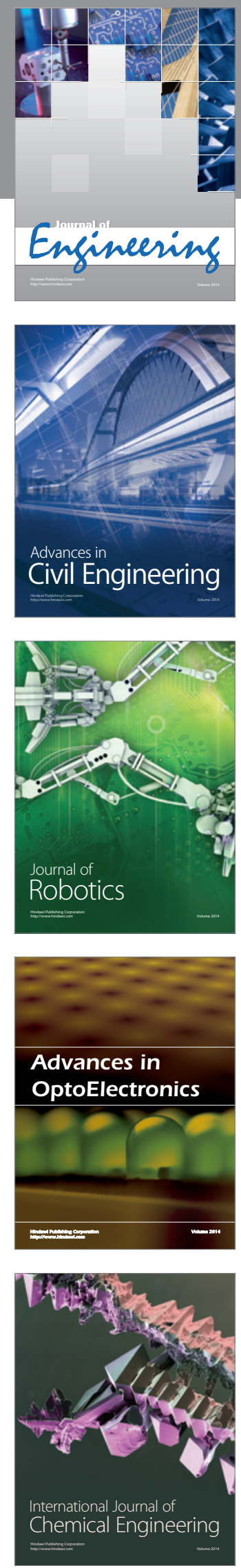

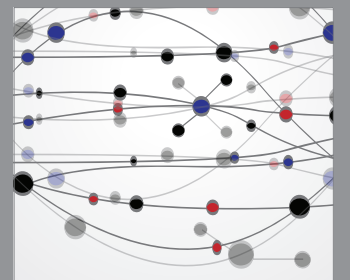

The Scientific World Journal
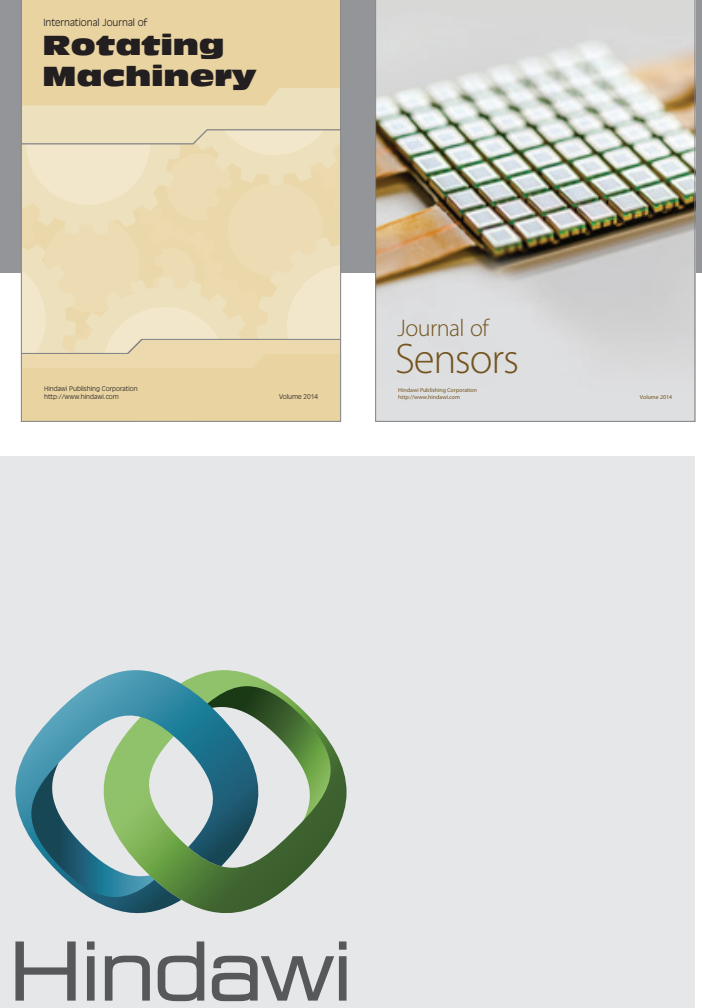

Submit your manuscripts at http://www.hindawi.com
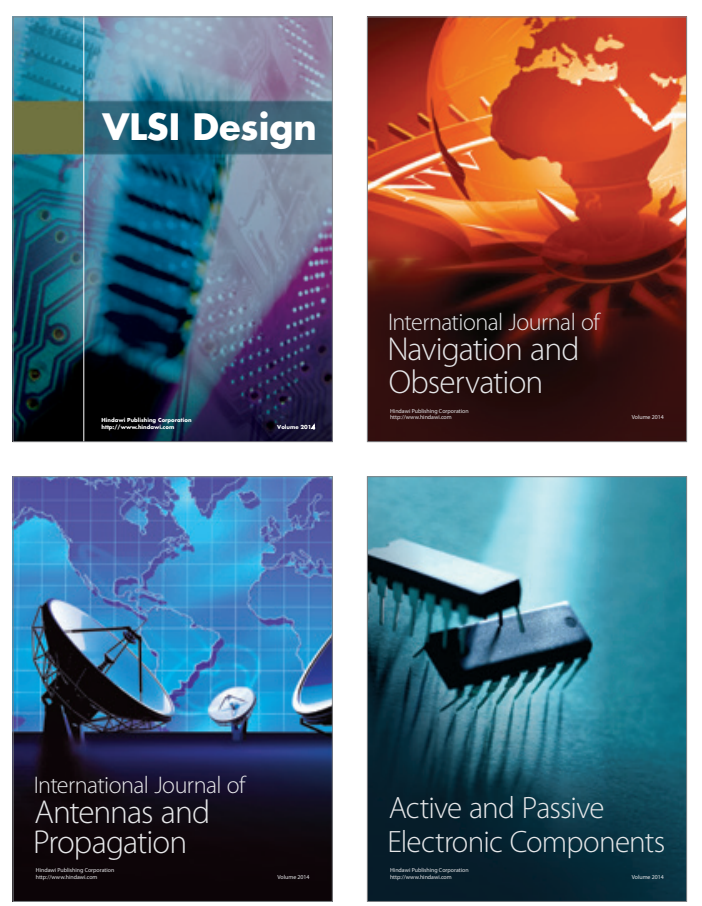
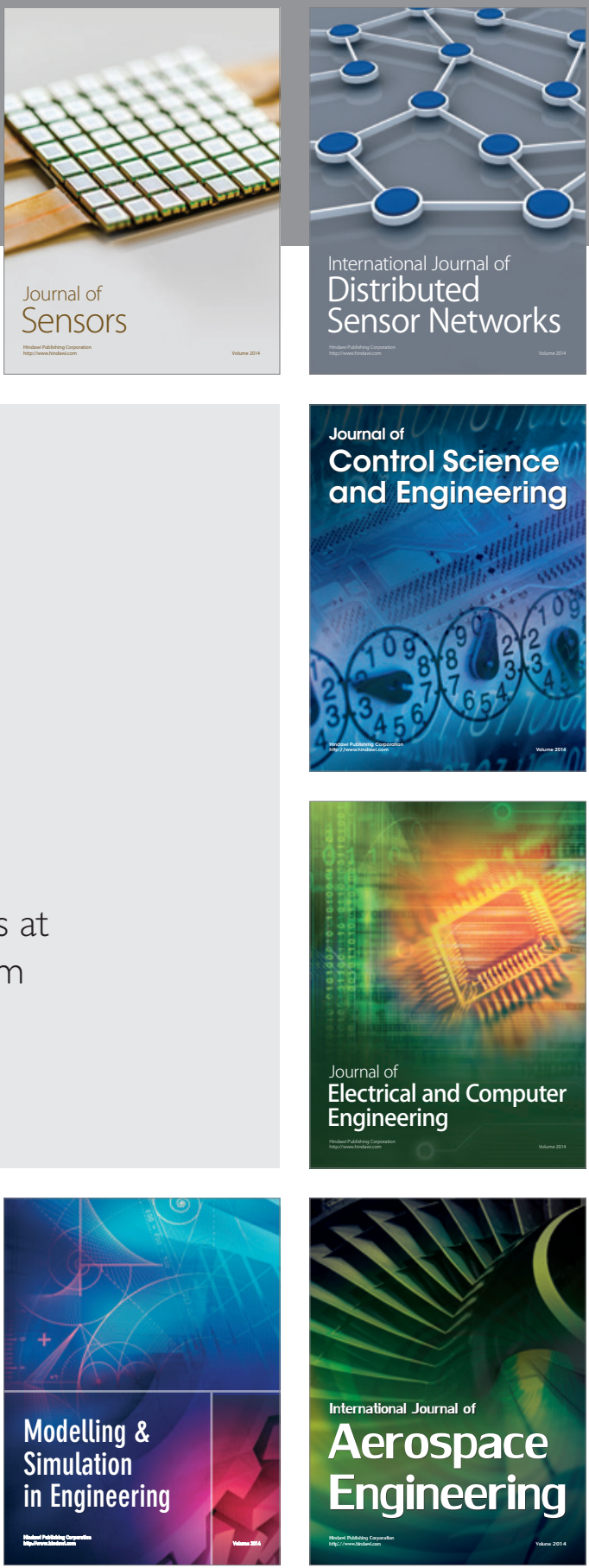

Journal of

Control Science

and Engineering
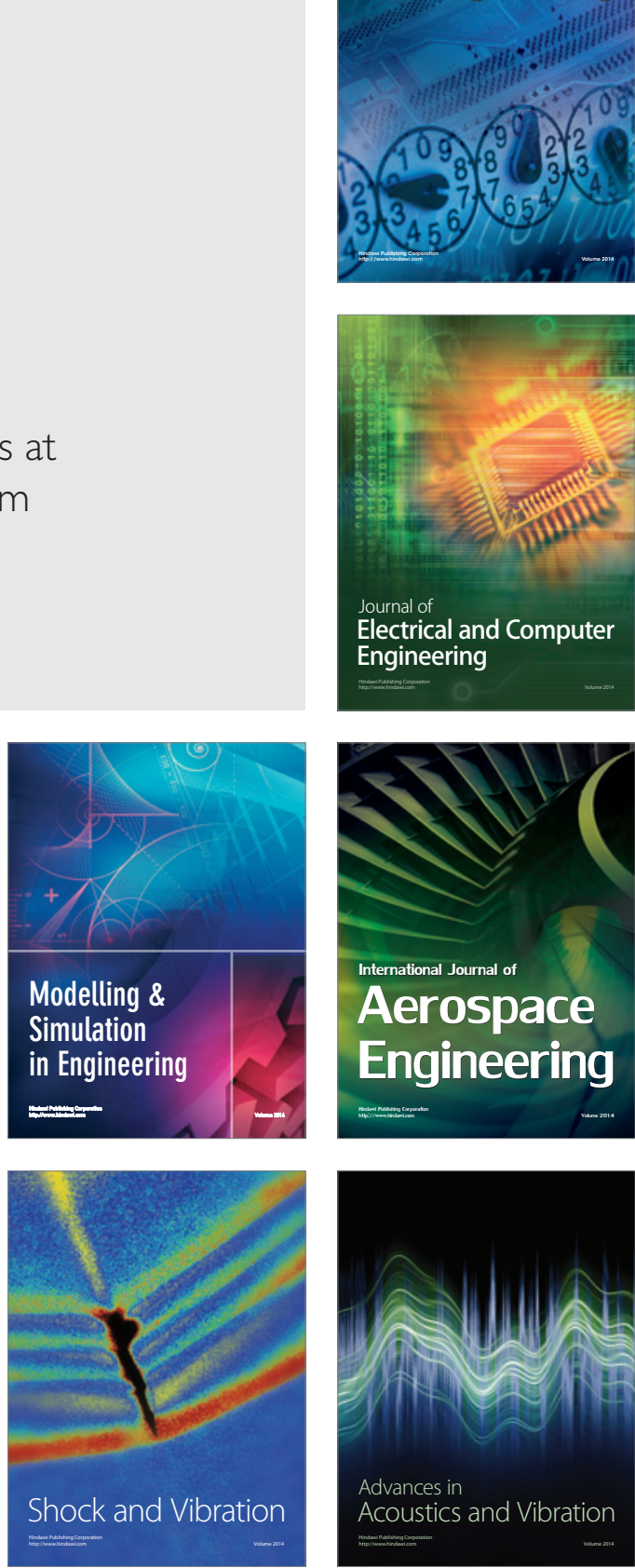